\title{
Traffic Flow Prediction in Urban Area Using Inverse Approach of Chaos Theory
}

\author{
Nur Hamiza Adenan ${ }^{1, *}$, Nor Suriya Abd Karim ${ }^{1}$, Adib Mashuri ${ }^{2}$, Nor Zila Abd Hamid ${ }^{1}$, \\ Mohd Shahriman Adenan ${ }^{3}$, Armansyah $^{4}$, Ikhsan Siregar ${ }^{5}$ \\ ${ }^{1}$ Department of Mathematics, Faculty of Science and Mathematics, Universiti Pendidikan Sultan Idris, 35900 Tanjong Malim, Perak, \\ Malaysia \\ ${ }^{2}$ Kolej Vokasional Batu Lanchang, 11600 Jelutong, Pulau Pinang, Malaysia \\ ${ }^{3}$ Smart Manufacturing Research Institute, Universiti Teknologi MARA, 40450 Shah Alam, Malaysia \\ ${ }^{4}$ Department of Industrial Engineering, Faculty of Engineering, Bina Nusantara University, 11480 Jakarta, Indonesia \\ ${ }^{5}$ Department of Industrial Engineering, Faculty of Engineering, Universitas Sumatera Utara, 22200 Sumatera Utara, Indonesia
}

Received January 28, 2021; Revised March 18, 2021; Accepted May 30, 2021

\section{Cite This Paper in the following Citation Styles}

(a): [1] Nur Hamiza Adenan, Nor Suriya Abd Karim, Adib Mashuri, Nor Zila Abd Hamid, Mohd Shahriman Adenan, Armansyah, Ikhsan Siregar , "Traffic Flow Prediction in Urban Area Using Inverse Approach of Chaos Theory," Civil Engineering and Architecture, Vol. 9, No. 4, pp. 1277 - 1282, 2021. DOI: 10.13189/cea.2021.090429.

(b): Nur Hamiza Adenan, Nor Suriya Abd Karim, Adib Mashuri, Nor Zila Abd Hamid, Mohd Shahriman Adenan, Armansyah, Ikhsan Siregar (2021). Traffic Flow Prediction in Urban Area Using Inverse Approach of Chaos Theory. Civil Engineering and Architecture, 9(4), 1277 - 1282. DOI: 10.13189/cea.2021.090429.

Copyright $\mathrm{C} 2021$ by authors, all rights reserved. Authors agree that this article remains permanently open access under the terms of the Creative Commons Attribution License 4.0 International License

\begin{abstract}
Traffic congestions problem could affect everyday life especially in urban area. In order to solve the issue, an excellent traffic flow prediction needs to be developed for a better traffic management. Hence, this study was conducted in order to predict traffic flow by using the data of total volume of vehicles per hour at two main roads located in urban areas namely Selangor and Kuala Lumpur, Malaysia by using application of chaos theory. Phase space reconstruction was used to determine the chaotic behaviour of the total volume of vehicles per hour data. The reconstruction of phase space involves a single variable of the total volume of vehicles per hour data to $m$-dimensional phase space. Meanwhile, the inverse approach as well as local linear approximation method was used to develop prediction model of the traffic flow time series data. This study found that (i) the time series data were chaotic behaviour based on the phase space plot and (ii) inverse approach can provide prediction on the traffic flow time series data besides give excellent prediction with the value of correlation coefficient more than 0.7500 . Hence, inverse approach of chaos theory can develop to prediction model towards the traffic flow in urban area; thus may help the local authorities to provide good traffic management.
\end{abstract}

Keywords Phase Space Reconstruction, Traffic Flow,
Urban, Inverse Approach, Nonlinear Prediction Method, Local Linear Approximation Method

\section{Introduction}

Traffic congestion is a normal scenario to be seen in urban areas while it can also endanger human and environment and can cause pollution [1]. Traffic flow prediction is important for traffic management as it provides accurate information for excellent traffic system [2]. Thus, efficient prediction of traffic flows can therefore help to monitor and analyse urban traffic needs and give citizens better choices of public transport [3]. As such, a prediction model that can give an accurate prediction of traffic flow has become a crucial need nowadays which gives a strong reason for its study and development.

Traffic flow or the total number of vehicles crossing a particular point per unit time period is a point process [4]. Traffic flow is a continuous phenomenon. The irregular patterns in the data show the complexity of the traffic system. The system is influenced by several variables such as volume, speed, density, travel time, and headways, which are important in traffic planning and design 
processes [5]. Hence, the multivariable analysis approach such as Bayesian network (BN) [6], artificial neural network (ANN) [5,7], auto-regressive integrated moving average (ARIMA) [4], deep neural network [8] and hybrid traffic prediction scheme using ARIMA-ANN [1] have been widely used in traffic flow analysis. These models and methods view traffic flow as random process. However, chaos phenomena illustrate the essence of complex process as not random, but it is caused by the chaos in nonlinear dynamics systems $[2,9]$.

Chaos approach involves reconstruction of phase space of the vehicle per hour time series data to multi-dimensional phase space. Then, the outcome from phase space reconstruction will be used in the prediction phase. The application of chaos approach in modelling the prediction of traffic flow time series data in Malaysia is still in the early stage. Until today, chaos approach has been applied to meteorology and hydrology areas in predicting ozone concentration and river flow in Malaysia [10-12] but no study on traffic management using chaos approach has been conducted.

There are many researches on chaos approach in traffic flow time series data have been carried out in some countries such as China [2,13], Iran [14] and Los Angeles [15]. Therefore, chaos approach needs to be applied to determine the suitability of this approach to the traffic flow time series data in Malaysia. Hence, the focus of this research is to determine the chaos existence and hence predict the traffic flow by investigating the volume of vehicles per hour in urban areas.

\section{Data}

Regular activities can lead to traffic congestion in areas with high distribution of population. Selangor and Kuala Lumpur are among the areas in Malaysia that have high population density (Department of Statistics Malaysia, 2011). This study was carried out on these two areas involving two stations at Klang-Sabak Bernam (BR807) and Kuala Lumpur-Karak (BR902).

Data provided by Highway Department Division, Ministry of Work, Malaysia (MoW) were available for data regarding traffic flow on Average Daily Traffic (ADT), Vehicle Classification (VC) and Peak Hour Volume (PHV). This study used data on ADT in order to predict traffic flow by obtaining the traffic volume which involved vehicles per hour time series data. Data on ADT were obtained by manual classical traffic count (MCC) conducted by Highway Department Division for seven continued days in March and September every year.

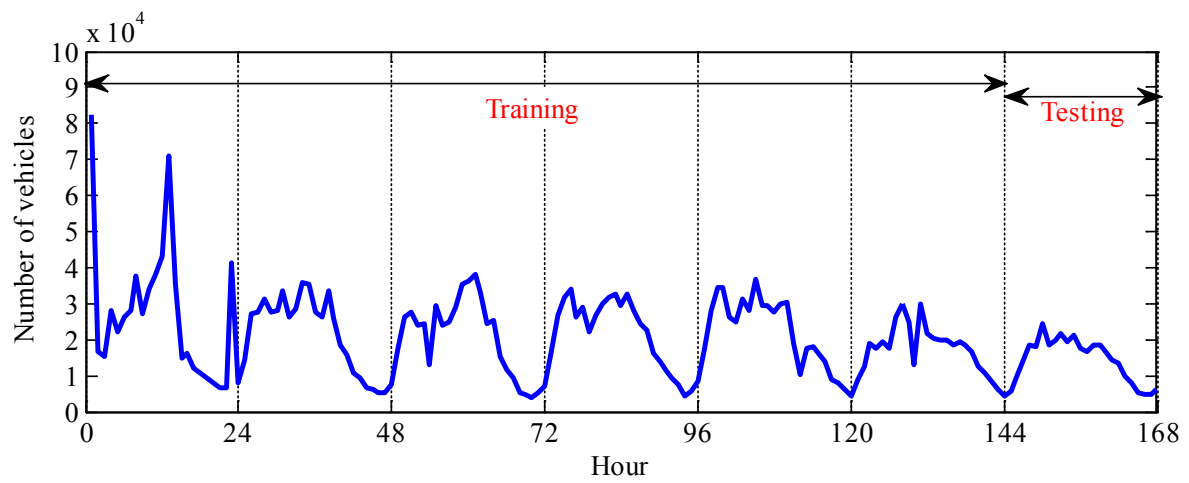

(a)

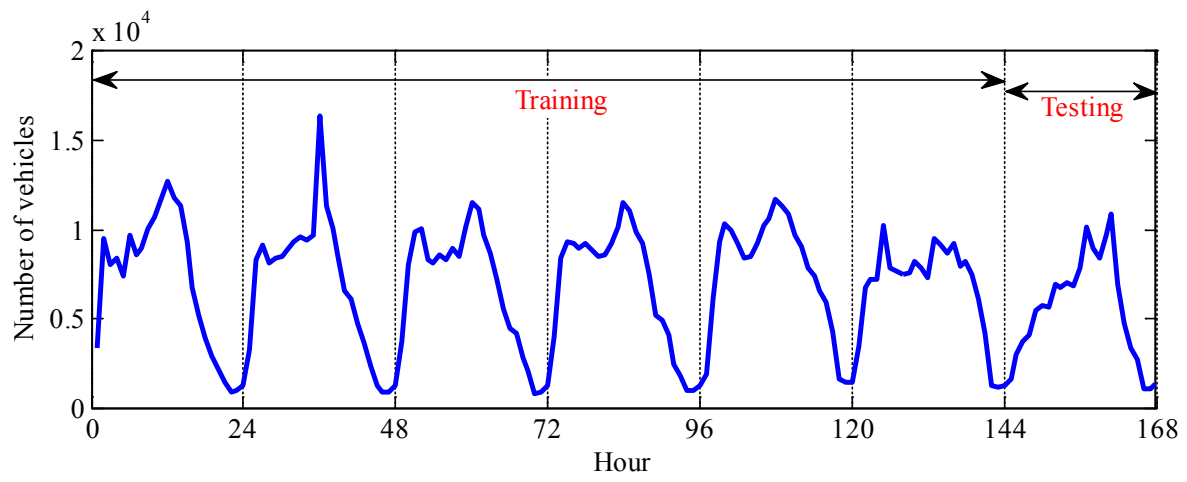

(b)

Figure 1. The number of vehicles per hour at (a) BR807 and (b) BR902 
This study used data from $22^{\text {nd }}$ September 2014 until $28^{\text {th }}$ September 2014 that were taken hourly. The whole 7-day dataset was divided into two parts; (i) training set: the first 6 days of data and testing set: subsequent 1 day. The training set was used to reconstruct the phase space meanwhile the testing set was used as observed data in the prediction phase. The variations of the total vehicles per hour that went through Klang - Sabak Bernam path (BR807) and Kuala Lumpur - Karak path (BR902), respectively which consisted of 168 data in each path showed in Figure 1 (a) and (b). The highest vehicles' volume that went through Klang - Sabak Bernam path in both directions reached 80000 vehicles per hour. Meanwhile, the highest vehicles' volume that used Kuala Lumpur - Karak path in both directions reached less than 20000 vehicles per hour. According to graphs in Figure 1, data on traffic flow were in seasonal pattern where the existence of peak and off-peak vehicles volume happened at almost the same time interval. Therefore, it is important to determine the chaotic existence in this data and hence predict the traffic flow in these two urban areas.

\section{Methodology}

\subsection{Chaotic Behaviour Determination Using Phase Space Plot}

Time series data with chaotic behaviour were divided into two categories which are deterministic and random [17]. Deterministic time series data can be predicted while random time series data are unpredictable. The main reason for detecting chaotic behaviour is to develop short term prediction model [18]. There are several methods used to determine the existence of chaotic behaviour on various time series data such as phase space plot [19], correlation dimension [20] and Cao method [10]. However, this study used phase space plot in order to determine the existence of chaotic behaviour in traffic flow time series data that were observed hourly. The phase space plot has been chosen in this study because chaotic behaviour can be identified clearly if there exists attractor in the phase space plot.

An appropriate phase space needs to be reconstructed in order to develop a phase space plot. Phase space reconstruction refers to one-dimensional univariate time series data which is the number of vehicles. Suppose that $\boldsymbol{X}$ is the number of vehicles and constructed in the form of:

$$
X=\left(x_{1}, x_{2}, x_{3}, \ldots, x_{N-1}, x_{N}\right)
$$

where $\boldsymbol{x}_{\boldsymbol{t}}$ is the number of vehicles per hour for $t=$ $1,2,3, \ldots, \quad N$. The $N$ is total number of data that is $N=168$.
The phase space can be reconstructed into $m$-dimensional phase space with:

$$
\mathbf{Y}_{j}=\left(x_{j}, x_{j+\tau}, x_{j+2 \tau}, \ldots, x_{j+(m-1)}\right)
$$

with $j=1,2, \ldots, N-(m-1) \tau$ where $\mathbf{Y}_{j} \in \mathrm{R}^{m}$. Refer to (2), parameter $\tau$ is the time delay and $\boldsymbol{m}$ is the embedding dimension. In order to plot 2-dimensional phase space plot, the value of $\tau$ is fixed as 1 and $\boldsymbol{m}=2$. The system is said to be in chaotic behaviour or we can say that the chaotic exists in the system if there exists attractor in the plotted phase space [21].

\subsection{Prediction Using Inverse Approach of Nonlinear Prediction Method}

The inverse approach by Sugihara and May [22] was used in predicting the number of vehicles per hour since this method does not require a lot of data [23]. This method is convenient to this study as this study involved 168 data. Furthermore, inverse method could help to calculate the dimension in order to determine a possible optimal dimension. An optimal embedding dimension can propose the possibility of low-dimensional chaos in a system [21]. Optimal dimension by inverse method can be defined by varying the values of $m$ from 2 to 10 in (2). The optimal value of $m$ is determined when the prediction gives the best value of correlation coefficient (CC).

The local linear approximation method has been used in prediction process. The time series data on the number of vehicles, $\boldsymbol{X}$ is divided into two parts which are $X_{\text {traning }}=\left(x_{1}, x_{2}, x_{3}, \ldots, x_{144}\right)$ that are data on the first six days and $X_{\text {tessing }}=\left(x_{145}, x_{146}, x_{147}, \ldots, x_{168}\right)$ that are data on the seventh day. The $X_{\text {training }}$ is used for prediction process. Meanwhile, the $X_{\text {testing }}$ is used to test the accuracy of the prediction results. Next, the relationship between the current state $\mathbf{Y}_{j}$ and the future state $\mathbf{Y}_{j+T}$ needs to be fulfilled using:

$$
\mathbf{Y}_{j+T}=f_{T}\left(\mathbf{Y}_{j}\right)
$$

In order to have an appropriate expression for $f_{T}$, the local linear approximation by Farmer and Sidorowich [24] will be used. The least square method has been used to determine the parameters $A$ and $B$ in order to predict using local linear approximation method using:

$$
\mathbf{Y}_{j+T}=A \mathbf{Y}_{j}+B
$$




\section{Results and Discussion}

Reconstruction of phase space using $\tau=1$ and $m=2$ has been developed as referring to (2) in order to plot 2-dimensional phase space. Both Figure 1 and Figure 2 portray the behaviour of the data that is the behaviour of traffic flow where Figure 2 shows the phase space plot in determining the chaotic existence for data in both stations. The evolution of the overall data has been transformed to 2-dimensional phase space as shown through the phase space trajectories of an attractor as seen in Figure 2. Refer to Figure 2, the phase space plot showed that there exist a well define attractor between $x$-axis and $y$-axis. Hence, the chaotic behaviour is present as there exists a well-defined attractor as referred to the research by Sivakumar [21]. Therefore, the behaviour is categorized as chaotic behaviour.

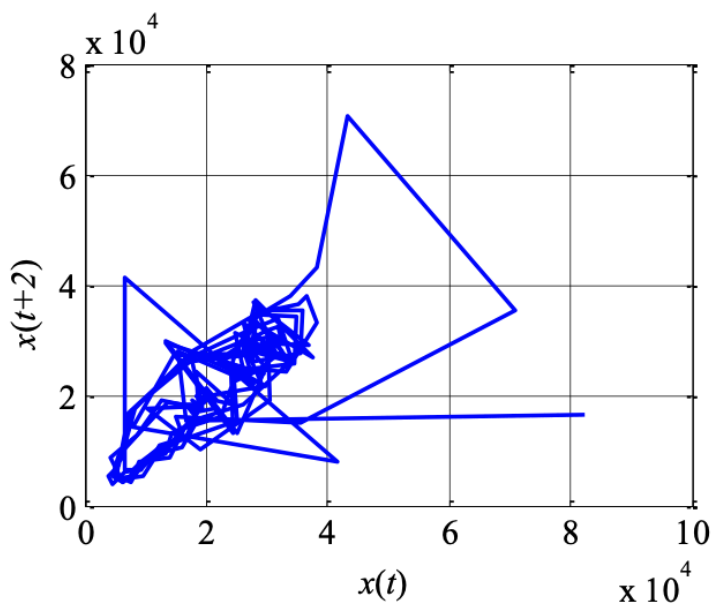

(a)

Table 1. Variation of embedding dimension for total vehicles per hour time series data using inverse approach at (a) BR807 and (b) BR902

a)

\begin{tabular}{|c|c|c|}
\hline \multirow{10}{*}{ a) } & $m$ & $C C$ \\
\hline & 2 & 0.7763 \\
\hline & 3 & 0.7359 \\
\hline & 4 & 0.7216 \\
\hline & 5 & 0.7460 \\
\hline & 6 & 0.3876 \\
\hline & 7 & 0.4970 \\
\hline & 8 & 0.3458 \\
\hline & 9 & 0.5181 \\
\hline & 10 & 0.5468 \\
\hline
\end{tabular}

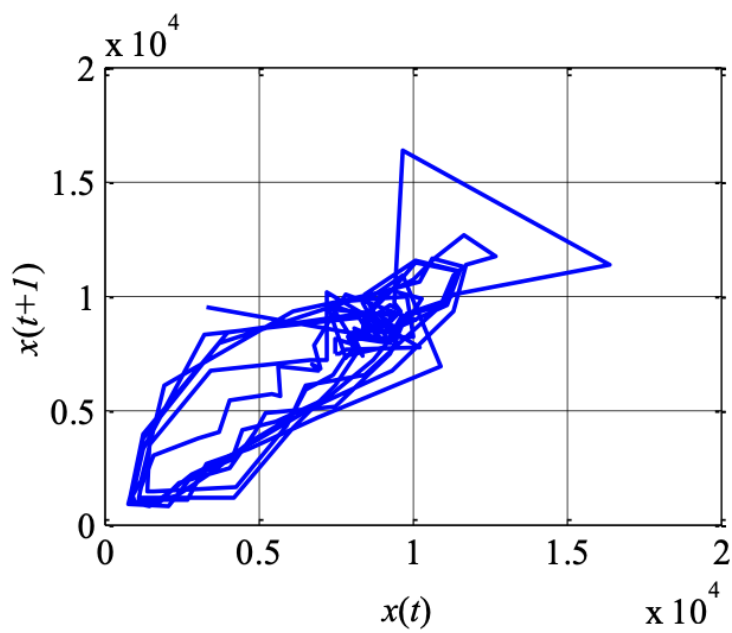

(b)

Figure 2. Phase space plot of traffic flow data at (a) BR807 and (b) BR902 using the combination of parameters

Referring to Figure 3, observed time series data as well as prediction result were plotted against time (hourly). The prediction result gave well accuracy from beginning to the end of prediction by comparing it to observed data. The prediction phase was conducted using inverse approach and local linear approximation method while the performance of the results was presented in terms of correlation coefficient $(C C)$ in Table 1. The embedding dimension $\boldsymbol{m}=2$ for both paths at BR807 and BR902 gives the best prediction with values of $C C>0.7500$. Hence, an optimal embedding dimension that refers to the value of $m$ proposed that there is a possibility presence of low-dimensional chaos behaviour in a system [21]. Therefore, the combination of inverse method and local linear approximation method is suitable to predict traffic flow in urban area. b)

\begin{tabular}{|c|c|}
\hline $\boldsymbol{m}$ & $\boldsymbol{C C}$ \\
\hline $\mathbf{2}$ & $\mathbf{0 . 8 4 7 8}$ \\
\hline 3 & 0.8237 \\
\hline 4 & 0.7067 \\
\hline 5 & 0.8356 \\
\hline 6 & 0.7465 \\
\hline 7 & 0.8213 \\
\hline 8 & 0.6690 \\
\hline 9 & 0.7932 \\
\hline 10 & 0.5957 \\
\hline
\end{tabular}




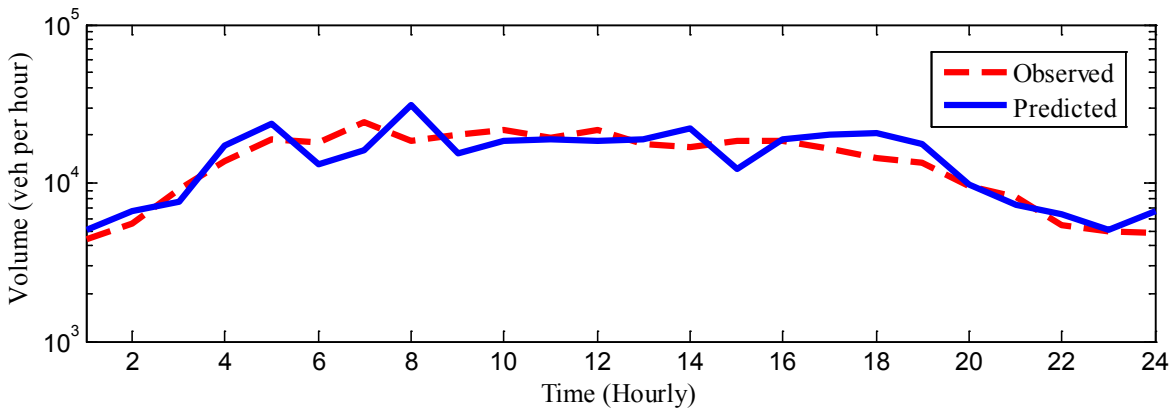

(a)

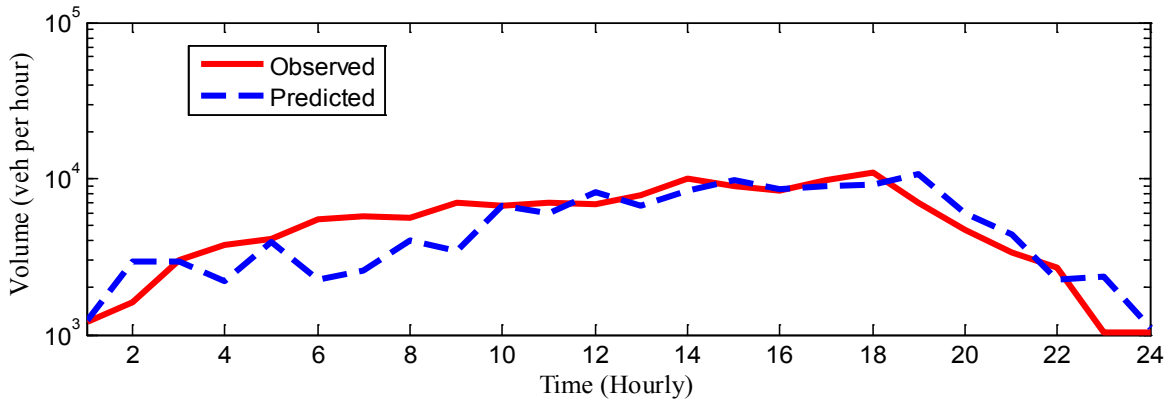

(b)

Figure 3. Prediction of hourly traffic flow time series data in (a) BR807 and (b) BR902 by comparison of observed-predicted results

\section{Conclusion}

Traffic flow in urban areas was represented by total vehicles per hour that were located at two paths in Selangor and Kuala Lumpur respectively, which involved a total of 168 time series data that were investigated using chaos approach. The chaotic existence on the data set was determined using phase space plot where specific pattern of attractor occurred in boths paths. The prediction on the total number of vehicles was conducted using the combination of inverse approach and local linear approximation method at optimal embedding dimension, $\boldsymbol{m}=2$ which gave an excellent prediction of $C C>0.7500$ for each station. This study showed that inverse approach is suitable to predict traffic flow in Malaysia and hence can be applied in traffic flow time series data set in forecasting the traffic flow.

\section{Acknowledgements}

The authors thankfully acknowledged the financial support provided by Universiti Pendidikan Sultan Idris (GGPU: 2018-0075-106-01) as well as Highway Department Division, Ministry of Work, Malaysia (MoW) for providing the traffic flow data.

\section{REFERENCES}

[1] Xie J, Choi Y-K. Hybrid traffic prediction scheme for intelligent transportation systems based on historical and real-time data. Int J Distrib Sens Networks [Internet]. 2017 Nov 29 [cited 2018 Apr 12];13(11):155014771774500. Available from: http://journals.sagepub.com/doi/10.1177/15 50147717745009

[2] Jieni X, Zhongke S. Short-Time Traffic Flow Prediction Based on Chaos Time Series Theory. J Transp Syst Eng Inf Technol [Internet]. 2008 [cited 2018 Apr 5];8(5). Available from:

http://202.116.197.15/cadalcanton/Fulltext/21297_2014319 _102457_208.pdf

[3] Vlahogianni EI, Golias JC, Karlaftis MG. Short-term traffic forecasting: Overview of objectives and methods. Transp Rev [Internet]. 2004 Sep [cited 2018 Apr 12];24(5):533-57. Available from: http://www.tandfonline.com/doi/abs/10.108 0/0144164042000195072

[4] Vasantha Kumar S, Vanajakshi L. Short-term traffic flow prediction using seasonal ARIMA model with limited input data. Eur Transp Res Rev [Internet]. 2015 Sep 13 [cited 2018 Apr 12];7(3):21. Available from: http://link.springer.com/10 1007/s12544-015-0170-8

[5] Kumar K, Parida M, Katiyar VK. Short Term Traffic Flow Prediction for a Non Urban Highway Using Artificial Neural Network. Procedia - Soc Behav Sci [Internet]. 2013 Dec 2 [cited 2018 Apr 12];104:755-64. Available from: https://www.sciencedirect.com/science/article/pii/S1877042 813045618 
[6] Pascale A, Nicoli M. Adaptive Bayesian network for traffic flow prediction. In: 2011 IEEE Statistical Signal Processing Workshop (SSP) [Internet]. IEEE; 2011 [cited 2018 Apr 12]. p. 177-80. Available from: http://ieeexplore.ieee.org/docum ent/5967651/

[7] Tijani A, Yusuf SD, Loko AZ, Mundi AA. Evaluation of real time rain-rate on downlink satellite signal attenuation in Abuja, Nigeria. Educ J Sci Math Technol [Internet]. 2020 Apr 7 [cited 2020 Oct 2];7(1):29-38. Available from: https://ejournal.upsi.edu.my/index.php/EJSMT/index

[8] Hongsuk Y, HeeJin J, Sanghoon B. Deep Neural Networks for traffic flow prediction. In: 2017 IEEE International Conference on Big Data and Smart Computing (BigComp) [Internet]. IEEE; 2017 [cited 2018 Apr 12]. p. 328-31. Available from: http://ieeexplore.ieee.org/document/788168 7/

[9] Ahmad A. Pembinaan Lengkungan Peralihan Berbentuk C yang Memuaskan Data Interpolasi Hermite G 2. J Sci Math Lett [Internet]. 2020 Apr 7 [cited 2020 Oct 2]; 8(2): 2600-8718. Available from: https://doi.org/10.37134/jsml.v ol8.2.6.2020

[10] Mashuri A, Adenan NH, Hamid NZA. Determining the Chaotic Dynamics of Hydrological Data in Flood-prone Area. Civil Engineering and Architecture, 2019 Dec 1;7(6):71-6. DOI: $10.13189 /$ cea.2019.071408

[11] Ruslan AB, Hamid NZA. Application of Improved Chaotic Method in Determining Number of k-Nearest Neighbor for CO Data Series. Int J Eng Adv Technol. 2019 Sep;8(6S3):10-4.

[12] Hamid NZA, Noorani MSM. On Prediction of Subang, Selangor Daily Rainfall Data: An Application of Local Approximation Method. J Sains dan Mat. 2012;4(2):49-57.

[13] Shang Q, Lin C, Yang Z, Bing Q, Zhou X. Short-Term Traffic Flow Prediction Model using Particle Swarm Optimization-Based Combined Kernel Function-Least Squares Support Vector Machine Combined eith Chaos Theory. Adv Mech Eng [Internet]. 2016 Aug 24 [cited 2018 Apr 13];8(8):168781401666465. Available from: http://journals.sagepub.com/doi/10.1177/168781401666465 4

[14] Adewumi A, Kagamba J, Alochukwu A. Application of Chaos Theory in the Prediction of Motorised Traffic Flows on Urban Networks. Hindawi Publ Corp. 2016;
[15] Li Y, Jiang X, Zhu H, He X, Peeta S, Zheng T, et al. Multiple measures-based chaotic time series for traffic flow prediction based on Bayesian theory. Nonlinear Dyn [Internet]. $2016 \mathrm{Jul}$ 25 [cited 2018 Apr 13];85(1):179-94. Available from: http://link.springer.com/10.1007/s11071-016-2677-5

[16] Official D of SM. Population Distribution and Basic Demographic Characteristic Report 2010 [Internet]. Department of Statistics Malaysia Official. 2011 [cited 2020 Jul 24]. Available from: https://www.dosm.gov.my/v1/index .php? $\mathrm{r}=$ column/ctheme\&menu_id=L0pheU43NWJwRWVS ZklWdzQ4TlhUUT09\&bul_id=MDMxdHZjWTk1SjFzTzN kRXYzcVZjdz09

[17] Abarbanel HDI. Analysis of Observed Chaotic Data. New York, NY: Springer New York; 1996. (Institute for Nonlinear Science).

[18] Vlad S. Investigation of chaotic behavior in Euro-Leu exchange rate. J Appl Comput Sci Math. 2010;8(8):4-8.

[19]Zaim WNAWM, Hamid NZA, Noorani MSM. Peramalan Bahan Pencemar Ozon (O3) di Universiti Pendidikan Sultan Idris, Tanjung Malim Perak, Malaysia Mengikut Monsun dengan Menggunakan Pendekatan Kalut. Sains Malaysiana [Internet]. 2018 [cited 2018 Apr 13];46(12):2523-8. Available from: http://dx.doi.org/10.17576/jsm-2017-461230

[20] Albostan A, Önöz B. Implementation of Chaotic Analysis on River Discharge Time Series. Energy Power Eng. 2015 Mar 16;07(03):81-92.

[21] Sivakumar B, Jayawardena A. An investigation of the presence of low-dimensional chaotic behaviour in the sediment transport phenomenon. Hydrol Sci J. 2002 Jun;47(3):405-16.

[22] Sugihara G, May RM. Nonlinear forecasting as a way of distinguishing chaos from measurement error in time series. Nature [Internet]. 1990 Apr 19;344(6268):734-41. Available from: http://www.ncbi.nlm.nih.gov/pubmed/2330029

[23] Sivakumar B, Liong S-Y, Liaw C-Y, Phoon K-K. Singapore rainfall behaviour: Chaotic? J Hydrol Eng. 1999;4(1):38-48.

[24] Farmer J, Sidorowich J. Predicting chaotic time series. Phys Rev Lett [Internet]. 1987 Aug 24 [cited 2014 Jan 27];59(8):845-8. Available from: http://link.aps.org/doi/10. 1103/PhysRevLett.59.845 